\title{
Effect of calcium-channel blockers on calcium-phosphate metabolism in patients with end-stage renal disease
}

\author{
K. Lippuner, H.-J. Zehnder, J. P. Casez, R. Takkinen, C. Descoeudres and Ph. Jaeger \\ Policlinic of Medicine, University Hospital, Berne, Switzerland
}

\begin{abstract}
Background. After EDTA-induced hypocalcaemia, healthy volunteers treated with diltiazem display more severe hyperparathyroidism than subjects on felodipine studied under identical conditions. Therefore patients with end-stage renal disease (ESRD) and severe secondary hyperparathyroidism might be particularly sensitive to this side-effect.

Methods. To test this hypothesis, seven patients with ESRD on chronic haemodialysis ( 3 women and $4 \mathrm{men}$ ) with serum levels of intact PTH ranging from 204 to $675 \mathrm{pg} / \mathrm{ml}$ were studied both before and during the first $180 \mathrm{~min}$ of haemodialysis against a dialysate with low calcium concentration $(0.75 \mathrm{mmol} / 1, n=6$ and $1 \mathrm{mmol} / \mathrm{l}, n=1)$ under the following three experimental conditions: control, felodipine $(10 \mathrm{mg} / \mathrm{day})$ and diltiazem ( $120 \mathrm{mg}$ b.i.d.).

Results. At onset of dialysis, plasma phosphorus level was higher on diltiazem $(2.03 \pm 0.08 \mathrm{mM})$ than on felodipine $(1.64 \pm 0.10, P<0.02)$, and on the latter it was lower than in control condition $(1.88 \pm 0.16$, $P<0.02$ ). As a probable consequence, blood ionized calcium concentration was lower on diltiazem $(1.14 \mathrm{mM} \pm 0.02$, mean $\pm \mathrm{SEM})$ than on felodipine $(1.2 \pm 0.03, \quad P<0.05)$ or in control condition $(1.17 \pm 0.01$, NS $)$. There was a trend for intact PTH to be higher on diltiazem $(324 \pm 47 \mathrm{pg} / \mathrm{ml})$ than on felodipine $(246 \pm 55)$ or in control condition $(305 \pm$ $49)$ and 1,25-dihydroxyvitamin $D$ was higher indeed on diltiazem $(6.70 \pm 0.92 \mathrm{pg} / \mathrm{ml})$ than on felodipine $(4.75 \pm 0.91, P<0.02)$ or control $(3.87 \pm 0.62, P<$ 0.05 ). Area under the curve PTH over the first $60 \mathrm{~min}$ of dialysis was higher by $16 \pm 7 \%$ on diltiazem than on felodipine $(P<0.05)$.

Conclusions. While on diltiazem rather than on felodipine, patients with ESRD display higher plasma phosphorus levels, and slightly aggravate the degree of severity of hyperparathyroidism recorded during haemodialysis against low-calcium dialysate. The longterm effect of this new observation remains to be evaluated.
\end{abstract}

Correspondence and offprint requests to: Philippe Jaeger MD, Professor of Medicine and Director, Policlinic of Medicine, University Hospital, CH-3010 Berne, Switzerland.
Key words: calcitriol; diltiazem; felodipine; haemodialysis; parathyroid hormone

\section{Introduction}

During the last decade the mechanisms governing secondary hyperparathyroidism in patients with chronic renal insufficiency have progressively been elucidated. The consequences of reduction of $1 \alpha$ hydroxylase activity in the kidney in parallel to reduction of renal mass (diminished calcitriol production) have been localized not only at the level of the gut (insufficient calcium transport) and of the skeleton (blunted sensitivity to parathyroid hormone), but also at the level of the parathyroid gland itself (derepression of the prepro-PTH gene because of the lack of calcitriol).

Recently the potential role of drugs, in particular the calcium-channel blockers (CCB) to trigger secondary hyperparathyroidism has been addressed in several laboratories. Barth et al., however, could not find any significant change in serum calcium or intact PTH levels in dialysis patients receiving nifedipine either acutely or chronically [1]. In a study on 20 patients in dialysis, Guerin et al. also did not find any change in C-terminal PTH levels after 4 weeks on nicardipine [2]. On the other hand, CCB have been shown to modulate PTH secretion both in vitro [3-10] and in vivo under normal conditions [5,9-12]. Recently we demonstrated that diltiazem (but not felodipine), when given to healthy volunteers stimulates PTH secretion, the maximal effect being reached under hypocalcaemic conditions [13]. Since decreased calcaemia is a common feature of patients with chronic renal failure, this prompted us to evaluate the impact of diltiazem and of felodipine on parathyroid hormone secretion in patients with end-stage renal disease both at baseline and under haemodialysis-induced hypocalcaemia.

\section{Subjects and methods}

Seven patients ( 3 women, 4 men, mean age 72.5 years, range 60-82 years) on chronic haemodialysis for an average of 31 
months (12-72 months) were included in this study after informed written consent was obtained. Predialysis serum intact PTH levels ranged from 204 to $675 \mathrm{pg} / \mathrm{ml}$ (normal $10-65 \mathrm{pg} / \mathrm{ml}$ ). At time of inclusion, four patients were treated with CCB (nifedipine $n=2$, amlodipine $n=2$ ) because of hypertension, none of the patients received vitamin $D$ derivatives or aluminum-containing phosphate binders, and calcium carbonate was the sole phosphate binder given. The latter was kept unchanged throughout the study. Patients were instructed to keep dietary phosphorus intake constant while participating in the trial.

All patients were studied under three experimental conditions: after a minimum of 2 weeks without any CCB, after 2 weeks on felodipine $(10 \mathrm{mg} / \mathrm{day})$, and after 2 weeks on diltiazem ( $120 \mathrm{mg}$ b.i.d.). A washout period of 2 weeks was inserted between the two treatment regimens. Patients not previously treated with nifedipine or amlodipine were studied untreated first $(n=3)$, then on felodipine, and then on diltiazem. In the other patients, nifedipine or amlodipine was discontinued and replaced first by felodipine $(n=2)$ or diltiazem $(n=2)$; thereafter they received the crossed-over CCB and were finally studied in the control condition.

On all three experimental settings, patients were investigated in the morning under fasting condition, during the first $180 \mathrm{~min}$ of a $3-4 \mathrm{~h}$ dialysis session carried out with a cuprophane membrane at a flow rate of $250-450 \mathrm{ml} / \mathrm{min}$. To induce hypocalcaemia, a dialysis fluid with low calcium concentration was used $(0.75 \mathrm{mmol} / 1, n=6$ and $1 \mathrm{mmol} / 1$ $n=1$ ). For a given patient, dialysis parameters were kept identical on each of the three treatment conditions. Blood pressure was recorded at the start of the dialysis session. At times $0,15,30,45,60,90,120,150$ and $180 \mathrm{~min}$, blood was drawn from the arterial outlet of the fistula for measurement of the concentrations of ionized calcium, inorganic phosphorus, magnesium, intact $\mathrm{PTH}$, and vitamin $\mathrm{D}$ metabolites (the latter at times 0 and $180 \mathrm{~min}$ only). Basal values were also obtained for glucose and insulin concentrations.

Ionized calcium was measured in whole blood at bedside with an ion-selective electrode (ionized $\mathrm{Ca} / \mathrm{pH}$ analyser $\# 634$, Ciba Corning Diagnostica AG, Switzerland, normal range $1.15-1.30 \mathrm{mmol} / \mathrm{l}$ at $\mathrm{pH} 7.4)$. For other assays, blood was centrifuged and frozen at $-20^{\circ} \mathrm{C}$. Plasma inorganic phosphorus, magnesium and glucose were measured using standard techniques in the central laboratory at our Institution (normal range $0.74-1.55 \mathrm{mmol} / \mathrm{l}$ for phosphorus, $0.70-0.95 \mathrm{mmol} / \mathrm{l}$ for magnesium, and $3.66-5.55 \mathrm{mmol} / 1$ for glucose). Intact PTH was measured in serum by immunoradiometry, using two antibodies (Allegro, Nichols Institute, San Juan Capistrano, CA; normal range $10-65 \mathrm{pg} / \mathrm{ml}$, detection limit $\mathrm{lpg} / \mathrm{ml})$. Serum $25(\mathrm{OH}) \mathrm{D} 3$ and $1-25(\mathrm{OH})_{2} \mathrm{D} 3$ were assayed with a commercial kit (Nichols Institute, normal range $6-40 \mathrm{ng} / \mathrm{ml}$ and $25-79 \mathrm{pg} / \mathrm{ml}$ respectively). Insulin was measured in plasma by radioimmunoassay (Pharmacia Biotech Europe, Brussels, Belgium) (normal range 4-30 $\mathrm{mU} / 1$ ).

Results at different times during the haemodialysis session were expressed as means \pm SEM of absolute values as well as of percentage change from control condition. Statistical analysis was performed with ANOVA for repeated measurements and Wilcoxon signed-rank test.

\section{Results}

\section{Baseline values (Table I [ $t_{0}$ ], Figure I)}

Systolic blood pressure was lower under both $\mathrm{CCB}$ treatments than under control condition, with no difference between the $\mathrm{CCB}$ treatment periods.

On diltiazem there was a tendency for blood ionized
Table 1. Mean values $\pm S E M$ at baseline and after $180 \mathrm{~min}$ of haemodialysis co, control; fdp, felodipine; dtz, diltiazem

\begin{tabular}{|c|c|c|c|c|}
\hline & & $\begin{array}{l}\text { to } \\
(\text { mean } \pm S E M)\end{array}$ & $\begin{array}{l}\mathrm{t} 180 \\
(\text { mean } \\
\text { SEM })\end{array}$ & $P$ \\
\hline \multirow[t]{3}{*}{ BP syst $(\mathrm{mmHg})$} & co & $156 \pm 8$ & $133 \pm 9$ & 0.04 \\
\hline & $\mathrm{fdp}$ & $138 \pm 8^{*}$ & $124 \pm 4$ & NS \\
\hline & $\mathrm{dtz}$ & $142 \pm 9^{*}$ & $119 \pm 8$ & 0.04 \\
\hline \multirow[t]{3}{*}{ BP diast $(\mathrm{mmHg})$} & co & $83 \pm 5$ & $72 \pm 4$ & 0.03 \\
\hline & fdp & $81 \pm 3$ & $68 \pm 3$ & 0.02 \\
\hline & $\mathrm{dtz}$ & $80 \pm 5$ & $75 \pm 4$ & NS \\
\hline \multirow[t]{3}{*}{$\mathrm{Ca}++(\mathrm{mM})$} & co & $1.17 \pm 0.01$ & $0.97 \pm 0.03$ & 0.02 \\
\hline & fdp & $1.20 \pm 0.03$ & $0.95 \pm 0.02$ & 0.02 \\
\hline & $\mathrm{dtz}$ & $1.14 \pm 0.02 \dagger$ & $0.94 \pm 0.04$ & 0.02 \\
\hline \multirow[t]{3}{*}{$\mathrm{Mg}(\mathrm{mM})$} & co & $1.22 \pm 0.04$ & $1.12 \pm 0.02$ & 0.03 \\
\hline & $\mathrm{fdp}$ & $1.23 \pm 0.00$ & $1.17 \pm 0.04$ & NS \\
\hline & $\mathrm{dtz}$ & $1.25 \pm 0.04$ & $1.14 \pm 0.03$ & 0.03 \\
\hline \multirow[t]{3}{*}{$P(\mathrm{mM})$} & co & $1.88 \pm 0.16$ & $0.76 \pm 0.06$ & 0.02 \\
\hline & fdp & $1.64 \pm 0.10^{* *}$ & $0.72 \pm 0.02$ & 0.02 \\
\hline & $\mathrm{dtz}$ & $2.03 \pm 0.08_{+}^{+}$ & $0.72 \pm 0.09$ & 0.02 \\
\hline \multirow[t]{3}{*}{ PTH $(\mathrm{pg} / \mathrm{ml})$} & co & $305 \pm 49$ & $540 \pm 88$ & 0.02 \\
\hline & fdp & $246 \pm 55$ & $550 \pm 96$ & 0.02 \\
\hline & $\mathrm{dtz}$ & $324 \pm 47$ & $569 \pm 107$ & 0.02 \\
\hline \multirow{3}{*}{$25-(\mathrm{OH}) \mathrm{D} 3(\mathrm{ng} / \mathrm{ml})$} & co & $18.3 \pm 2.3$ & $18.6 \pm 2.0$ & NS \\
\hline & fdp & $18.1 \pm 2.2$ & $18.2 \pm 2.0$ & NS \\
\hline & $\mathrm{dtz}$ & $20.1 \pm 3.1$ & $20.0 \pm 2.9$ & NS \\
\hline \multirow{3}{*}{$1,25-(\mathrm{OH})_{2} \mathrm{D} 3(\mathrm{pg} / \mathrm{ml})$} & co & $3.87 \pm 0.62$ & $5.00 \pm 0.43$ & NS \\
\hline & $\mathrm{fdp}$ & $4.75 \pm 0.91$ & $6.65 \pm 1.64$ & NS \\
\hline & $\mathrm{dtz}$ & $6.70 \pm 0.92^{*} \ddagger$ & $6.16 \pm 0.76$ & NS \\
\hline
\end{tabular}

$* P<0.05$ vs co, $+P<0.05$ vs fdp.

** $P<0.02$ vs co, $\ddagger P<0.02$ vs fdp (Wilcoxon signed rank test).

calcium concentration to be lower $(P=0.09, \mathrm{~ns})$ and for intact PTH level to be higher $(P=0.39, \mathrm{NS})$ than under control condition; on felodipine, inverse trends were observed. None of these differences, however, reached statistical significance, whereas blood ionized calcium concentration was significantly lower on diltiazem than on felodipine $(P<0.05)$. It has to be noted, however, that after exclusion of one outlier with particularly high intact PTH levels at the beginning of the study (Figure 1, patient B), the difference between PTH levels under felodipine and those under diltiazem were statistically significant $(P=0.03)$.

In all patients, 25(OH)D3 serum levels were within the normal range, without difference among the three groups. In all patients, $1,25(\mathrm{OH})_{2} \mathrm{D} 3$ serum concentrations were below the normal range; under diltiazem; however, mean value was significantly higher than on the other two regimens $(P<0.05$ vs control; $P<0.02$ vs felodipine). Plasma magnesium concentrations were above the normal range in all patients, and so were plasma phosphorus levels in five patients of seven. In the seven patients plasma phosphorus concentration on diltiazem (dtz) was higher than on felodipine (fdp) $(P<0.02)$ and the latter was lower than in control (co) condition $(P<0.02)$. Serum concentrations of glucose (co, $4.63 \pm 0.18 \mathrm{mM}$; fdp, $4.86 \pm 0.40 ; \mathrm{dtz}, 4.66 \pm 0.17$ ) and of insulin (co, $10.94 \pm 2.97 \mathrm{mU} / \mathrm{l} ; \mathrm{fdp}, 14.11 \pm 4.50$; $\mathrm{dtz}, 10.00 \pm 2.25$ ) were identical in the three treatment conditions. Moreover, none of the treatments altered the correlation serum glucose vs insulin levels ( $y=$ $\left.0.059+4.030, n=21, r^{2}=0.546, P=0.0043\right)$. 

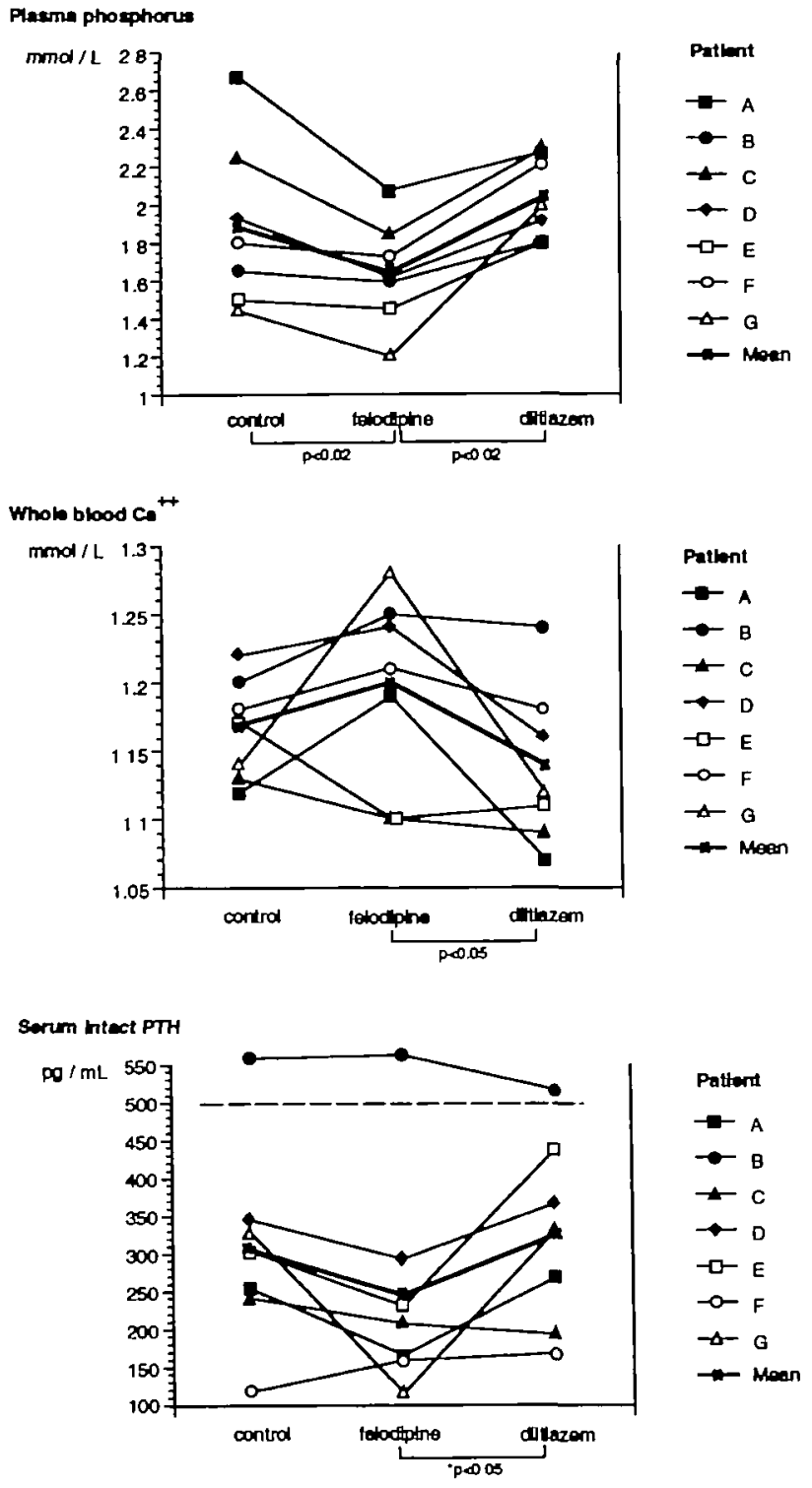

Fig. 1. Individual concentrations of plasma phosphorus, whole blood ionized calcium, and serum intact PTH obtained after 2 weeks under three different experimental conditions: no calcium channel blockers (control), felodipine, or diltiazem. *After exclusion of patient $\mathbf{B}$.

\section{Relevant values after 180 min on dialysis (Table $1, t_{180}$ )}

As a consequence of haemodialysis, plasma phosphorus concentrations decreased dramatically below the normal range in all three experimental groups $(P=$ 0.02). Plasma magnesium concentrations decreased slightly both under control condition and on diltiazem $(P=0.03)$ but not on felodipine; however, all postdialysis values remained over the normal range.

Changes in plasma phosphorus, blood ionized calcium, and serum intact PTH levels over dialysis time

Comparison of plasma phosphorus profiles (ANOVA for repeated measurements of the nine time points from 0 to $180 \mathrm{~min}$ ) during haemodialysis revealed

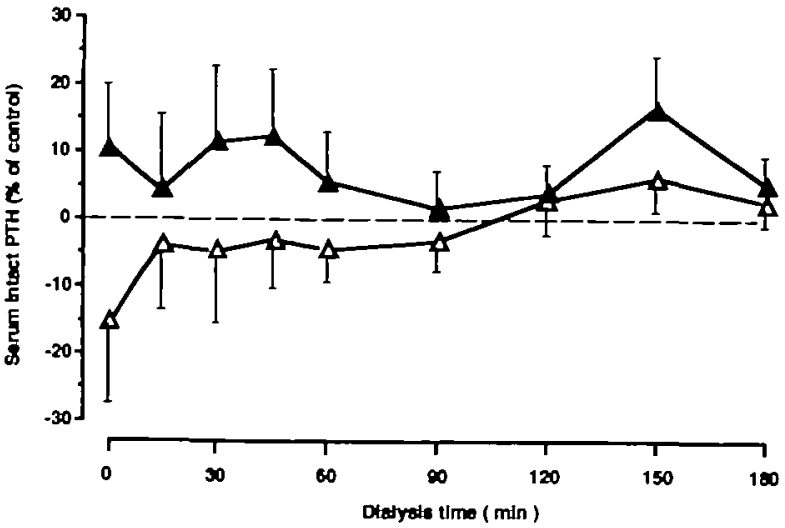

Fig. 2. Serum intact PTH concentrations on felodipine $(\triangle)$ or diltiazem $(\boldsymbol{\Delta})$ at different times of a haemodialysis session using a low-calcium bath. Results given as \% of values obtained without $\mathrm{CCB}$ treatment. Felodipine vs control, $P=0.1$ (for all time points); $P=0.016$ (for time points $0-120$ ); diltiazem vs control, $P=0.043$; diltiazem vs felodipine, $P=0.0001$ (ANOVA for repeated measurements for all time points).

higher values while patients were on diltiazem compared with felodipine $(P<0.001)$, and lower ones while they were on felodipine compared with control condition $(P<0.001)$, the latter curve being intermediate. However, initial differences in mean plasma phosphorus concentration gradually levelled off over haemodialysis time, being no longer statistically different from each other after the dialysis session.

Similarly, blood ionized calcium concentrations fell during haemodialysis under all experimental conditions. Taking all time points together, blood ionized calcium concentration was higher on felodipine than on diltiazem $(P<0.001)$ or under control condition $(P<0.05)$, whereas it was lower on diltiazem compared with control condition $(P<0.001)$. Again, over haemodialysis time, all differences progressively vanished.

Changes in intact PTH serum concentrations were a mirror image of those of blood calcium (Figure 2). Again, taking all time points together, intact PTH levels were higher on diltiazem than on felodipine $(P<0.001)$ and under control condition $(P<0.05)$, and considering only time points $0-120 \mathrm{~min}$, they were lower on felodipine than without any of these drugs $(P<0.02)$

Integrated parathyroid secretion over the first 60 min on dialysis can be represented by the area under the curve (AUC) of PTH/time. In six of the seven patients, AUC was higher on diltiazem than on felodipine, the mean difference being $16 \pm 7 \%(P<0.05)$.

\section{PTH/Ca concentrations relationship}

Figure 3 depicts the PTH/Ca response curves on the three experimental conditions: it is apparent that these relationships were virtually identical. In the absence of induced hypercalcaemia in this study, the calcium set points could not be calculated from these data, since in most cases baseline PTH concentrations were over $50 \%$ of maximal values. 


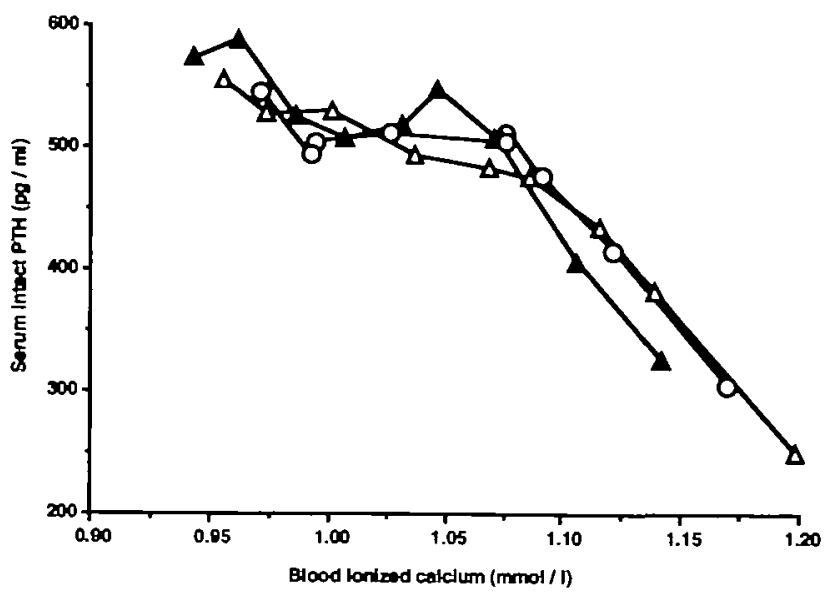

Fig. 3. Relationship between serum intact PTH and blood ionized calcium concentrations during a haemodialysis session using lowcalcium bath in seven patients receiving no CCB (O), felodipine $(\Delta)$ or diltiazem $(\mathbf{A})$.

\section{Discussion}

The present study shows that patients with end-stage renal disease (ESRD) who are treated with CCB have higher $(P<0.02)$ plasma phosphorus concentrations on diltiazem than on felodipine, and lower ones $(P<0.02)$ on felodipine than without any of these drugs. As a probable consequence of this, there were changes in blood ionized calcium levels which were lower on diltiazem than on felodipine as well as changes in serum PTH and $1,25(\mathrm{OH})_{2} \mathrm{D}$ concentrations, which were higher on diltiazem than on felodipine. However, maximal PTH concentrations under haemodialysisinduced hypocalcaemia were not significantly different under both treatment conditions, although the areas under the curves of the relationships serum PTH concentration over time were $16 \%$ higher on diltiazem than on felodipine $(P<0.05)$.

These results are in keeping with those recently obtained in healthy volunteers during EDTA-induced hypocalcaemia, which also showed more marked hyperparathyroidism on diltiazem than on felodipine [13]. In these subjects, however, maximal PTH concentrations under EDTA-induced hypocalcaemia were clearly higher on diltiazem than on felodipine.

Several explanations may be provided to account for this difference. Firstly, one has to realize that the levels of PTH reached at any time point by the ESRD patients of the present study are almost by one order of magnitude higher than those reached by the healthy subjects, i.e. a tremendously higher background noise. For PTH values ranging from 500 to $700 \mathrm{pg} / \mathrm{ml}$, relatively small differences in PTH for a given blood level of calcium cannot be expected to be detected in a population of seven ESRD patients, whereas within the range of PTH values obtained in normal subjects, such was possible between the diltiazem and the felodipine condition. Actually, after exclusion of one patient with particularly high intact PTH serum concentrations, mean PTH serum level was significantly higher
$(P<0.05)$ after treatment with diltiazem rather than with felodipine. Secondly, whereas hypocalcaemia induced by EDTA is a relatively pure disorder (with the exception of concomitant chelation of serum magnesium), hypocalcaemia induced by low-calcium haemodialysis is accompanied by a host of disturbances such as the changes in acid-base status, urea, phosphorus, and to a lesser extent magnesium concentrations, which may at least in part act independently on the Ca-PTH secretory axis. Thirdly, parathyroid hormone may be cleared by the haemodialysis process, especially when using polyacrylonitrile membranes; however, the clearance of intact PTH appears to be very small when using cuprophane membranes similar to those used in the present study [14].

Beyond the speculations around differences between both studies, two aspects of the observation in ESRD patients deserve special mention. One is technical and deals with the progressive reduction of the differences in plasma phosphorus, in blood ionized calcium as well as in serum intact PTH levels between the two treatment phases and the control conditions over the time course of the haemodialysis session, i.e. after 60 min: it reflects progressive equilibration between blood and dialysate compartments as well as clearance of the drug through the dialysis membrane. The other one deals with the apparent disturbance of phosphorus homeostasis in ESRD patients treated with CCB. Clearly, ESRD patients on diltiazem have higher plasma phosphorus concentrations than on felodipine and lower ones on felodipine than without these drugs. What is the reason for this?

The obvious explanation to consider first is noncompliance to the diet in an ambulatory setting. However, this view cannot hold if one remembers that the patients were randomly assigned to a sequence diltiazem-felodipine vs felodipine-diltiazem and that seven of seven patients had a higher plasma phosphorus concentration on diltiazem than on felodipine, a difference by about $25 \%$ on average.

In healthy volunteers CCB (e.g. verapamil) have not been shown to lead to any specific effect on serum concentrations of phosphate [15] and our previous studies on diltiazem and felodipine [13] have confirmed this point ${ }^{1}$. Under pathological conditions there is some evidence for direct interactions between CCB and phosphorus metabolism, but they are scarce. For instance, the protective effect of CCB against ischaemic damage has been associated with delayed cellular depletion of high-energy phosphate, be it in the brain with nimodipine [16], in the myocardium with nifedipine [17] and verapamil [18] or in the kidney with verapamil [19]. Such intracellular accumulations of phosphorus could not account for increments in plasma levels as observed with diltiazem, but could theoretically be invoked to decrements in plasma phosphorus levels

\footnotetext{
* Data on phosphorus were not reported in the paper. At baseline they were as follows: $1.23 \pm 0.075 \mathrm{mM}$ on diltiazem, vs $1.26 \pm 0.094 \mathrm{mM}$ on felodipine and $1.20 \pm 0.056 \mathrm{mM}$ on control condition $(P=\mathrm{ns})$.
} 
after felodipine. As an alternative it is known that CCB, like nifedipine and verapamil, can amplify the stimulatory action of insulin on cellular uptake of phosphate [20]. Again, this mechanism could not account for the data on diltiazem, but maybe for those on felodipine. However, a direct effect of diltiazem or of felodipine on basal insulin secretion has been reasonably excluded in the present study by the identical serum levels of glucose and insulin in both treatment conditions.

Verapamil has been shown to increase serum phosphate as well as urinary excretion rate of phosphate in patients with post-surgical hypoparathyroidism [21]: the mechanism postulated by the authors is a stimulation of bone resorption. However, in the present study a direct effect of CCB on bone would be hard to reconcile with the data on calcium and PTH concentrations.

Another explanation for differences in plasma phosphorus concentrations might be the different sideeffects of the two CCBs: nausea has been reported in patients under diltiazem, whereas it is rarely seen in patients under felodipine. However, since none of our patients reported nausea, this explanation is rather unlikely.

Therefore we are probably left with two possibilities which, to the best of our knowledge, have not been addressed so far: either a non-insulin-dependent druginduced shift of the equilibrium between intra- and extracellular phosphorus, or an effect of CCB on intestinal transport of phosphate, with opposite actions of diltiazem and felodipine which ESRD unmasks.

Whatever the mechanism, the present study confirms in patients with ESRD the trend for relative hyperparathyroidism on diltiazem versus felodipine previously noted in healthy volunteers [13], although the magnitude of the effect appears to be smaller in the former subjects than in the latter. Both drugs seem to affect the control of plasma phosphorus levels, which might thus require increments in the doses of phosphate binders while on diltiazem. Long-term studies on a larger population of such patients are needed, however, to evaluate the clinical significance of this new observation.

Acknowledgement. This study was supported by a research grant from Astra Pharmaceutical Company.

\section{References}

1. Barth RH, Leslie BR. Effect of nifedipine on serum PTH and calcium in dialysis patients with hyperparathyroidism. Kidney Int 1984; 25: 139 (Abstract)

2. Guerin AP, London GM, Marchais SJ, Metivier F, Safar ME, Sassano P. Parathyroid hormone and cardiovascular effects of dihydropyridines in chronic renal failure. AJH 1990; 3: 566-569
3. Millar JA, Struthers AD. Calcium antagonists and hormone release. Clin Sci 1984; 66: 249-255

4. Schőn RE, Frishman WH, Shamoon H. Hormonal and metabolic effects of calcium channel antagonists in man. $A m J ~ M e d$ 1988; 84: 492-504

5. Seely EW, Le Boff MS, Brown EM et al. The calcium channel blocker diltiazem lowers serum parathyroid hormone levels in vivo and in vitro. J Clin Endocrinol Metab 1989; 68: 1007-1012

6. Larsson $R$, Akerstrom $G$, Gylfe $E$ et al. Paradoxical effects of $\mathrm{K}^{+}$and $\mathrm{D}-600$ on parathyroid hormone secretion and cytoplasmic $\mathrm{Ca}^{2+}$ in normal bovine and pathological human parathyroid cells. Biochim Biophys Acta 1985; 847: 263-269

7. Cooper CW, Borowsky SA, Farrell PE, Steinsland OS. Effect of the calcium channel activator BAY-K-8644 on in vitro secretion of calcitonin and parathyroid hormone. Endocrinology 1986; 118: 545-549

8. Ramp WK, Cooper CW, Ross AJ, Wells SA Jr. Effects of calcium and cyclic nucleotides on rat calcitonin and parathyroid hormone secretion. Mol Cell Endocrinol 1979; 14: 205-215

9. Bernheim J, Kalinsky Z, Rathausa M, Shapira M. The influence of the calcium channel blocking agent nifedipine on the secretion of parathyroid hormone. In: Ornay A, Harell A, Sela J, eds. Current Advances in Skeletogenesis. Elsevier, Amsterdam, 1985; 161-164

10. Frishman WH, Klen NA, Charlap S et al. Comparative effects of verapamil and propranolol on parathyroid hormone and serum calcium concentration. In: Packer M, Frishman WH, eds. Calcium Channel Antagonists in Cardiovascular Diseases. Appleton Century Crofts, Norwalk, 1984; 343-349

11. Wynne AG, Romansky SA, Klee GG, Ory SJ, O'Fallon WM, Fitzpatrick LA. Effects of calcium channel antagonists on calciotropic hormones in women (Abstract). J Bone Miner Res 1991; 6 [Suppl 1]: 182

12. Albers MM, Johnson W, Vivian V, Jackson RD. Chronic use of the calcium channel blocker nifedipine has no significant effect on bone metabolism in men. Bone 1991; 12: 39-42

13. Villiger L, Casez J-P, Takkinen $\mathbf{R}$, Jaeger Ph. Diltiazem stimulates parathyroid hormone secretion whereas felodipine does not. J Clin Endocrinol Metab 1993; 76: 890-894

14. D'Amour P, Jobin J, Hamel L, L'Ecuyer N. Intact PTH values during haemodialysis: role of ionized calcium, dialysis membranes and intact-PTH assays. Kidney Int 1990; 38: 308-314

15. Joborn H, Bergstrom R, Rastad J, Wide L, Akerstrom G, Ljunghall S. Effects of propranolol and verapamil on plasma ionized calcium and parathyroid hormone in short-term intense isokinetic leg exercise. Clin Physiol 1988; 8: 1-7

16. Lemons V, Chehrazı BB, Kauten R, Hein L, Wagner FC Jr. The effect of nimodipine on high-energy phosphates and intracellular $\mathrm{pH}$ during cerebral ischemia. J Neurotrauma 1993; 10: 73-81

17. Sukehiro S, Dyszkiewics W, Minten J, Wynants J, Van Belle H, Flameng $\mathbf{W}$. Catabolism of high energy phosphates during longterm cold storage of donor hearts: effects of extra- and intracellular fluid-type cardioplegic solutions and calcium channel blockers. J Heart Lung Transplant 1991; 10:387-393

18. Neubauer S, Ingwall JS. Verapamil attenuates ATP depletion during hypoxia: $31 \mathrm{P}$ NMR studies of the isolated rat heart. $J$ Mol Cell Cardiol 1989; 21: 1163-1178

19. Aureli T, Miccheli A, Ricciolini R et al. Nuclear magnetic resonance spectroscopy study on kidney preservation. Effect of verapamil. Cell Mol Biol 1990; 36: 439-448

20. Abraham MI, McAteer JA, Kempson SA. Insulin stimulates phosphate transport in opossum kidney epithelial cells. $A m$ $J$ Physiol 1990; 258: 1592-1598

21. Sjoden G, Rosenqvist M, Nordenstrom J, Bjorkhem I, Eriksson SA, Kriegholm E. Verapamil increases serum ionized calcium and serum phosphate in patients with post-surgical hypoparathyroidism. Eur J Clin Invest 1992; 22: 378-382 